\title{
DESAFIOS DA FORMAÇÃO PARA A CONSTRUÇÃO DO PROJETO DE GESTÃO INTEGRADA DE TECNOLOGIAS EM ESCOLAS UCA EM MINAS GERAIS
}

\author{
Patrícia Maria Caetano de Araújo ${ }^{1,2}$, Simão Pedro P. Marinho ${ }^{2}$, Fernanda de \\ Jesus Costa ${ }^{1,2}$, Alessandra de Oliveira Reis ${ }^{2,3}$, Nédia de Oliveira ${ }^{2}$ \\ ${ }^{1}$ Universidade do Estado de Minas Gerais (UEMG) \\ ${ }^{2}$ Pontifícia Universidade Católica de Minas Gerais, Programa de Pós-graduação em Educação, \\ Grupo de Pesquisa Tecnologias Digitais e Educação (TDEduc). Equipe do Projeto UCA . \\ ${ }^{3}$ Projeto Reinventando o Ensino Médio, Governo do Estado de Minas Gerais \\ profpmca@yahoo.com.br
}

\begin{abstract}
This paper presents results of a research on the in-service teacher education in the stage of Integrated Management Project of Technologies in schools of the One Computer Per Child Project, UCA, in the state of Minas Gerais. It was used a questionnaire, with open questions, to identify the teachers' perceptions on facilitating factor and constraints on the training module. The teachers have a positive evaluation about the training module and offer some suggestions to overcome the issues that may be barriers in the training process.
\end{abstract}

\begin{abstract}
Resumo: Neste trabalho são apresentados resultados de uma pesquisa sobre a formação continuada dos profissionais da educação na etapa de elaboração de Projeto de Gestão Integrada de Tecnologias em escolas do Projeto Um Computador por Aluno, UCA, no Estado de Minas Gerais. Utilizou-se um questionário, com questões abertas, para identificar a percepção dos professores-cursistas sobre aspectos facilitadores e dificultadores na formação no módulo. Os cursistas fazem uma avaliação positiva quanto à formação e apresentam sugestões para a superação de aspectos que podem constituir barreiras no processo de formação.
\end{abstract}

\section{INTRODUÇÃO}

O Programa Um Computador por Aluno diferencia-se pela inserção da tecnologia móvel, com o uso individualizado, 1:1, de um laptop educacional com acesso permanente à internet. Em seu período de experimento-piloto, contou com um pouco mais do que quinhentas escolas participantes, em diferentes contextos, urbanas e rurais, em todas as unidades federativas.

O uso do laptop na perspectiva 1:1 ao ser idealizado para criar possibilidades de inovação pedagógica com a inserção das tecnologias digitais da informação e comunicação [TDIC] exigiu a formação de profissionais que atuam em várias instâncias da rede escolar (BRASIL,2007).

Os estudos de pesquisadores da área, bem como os princípios dos documentos normativos para o desenvolvimento da formação, o chamado Projeto Formação Brasil, indicam a atenção em dois aspectos a serem contemplados na formação de gestores e professores participante. Um deles está relacionado a inovação das práticas pedagógicas 
a serem desenvolvidas em sala de aula com o uso das TDIC. Outro, de caráter mais amplo, envolve discussões coletivas para implementação da integração das tecnologias no processo educativo com o comprometimento da escola (ALMEIDA; PRADO, 2010).

Destaca-se como um dos aspectos fundamentais no Projeto UCA a formação dos cursistas para a incorporação das TDIC, no uso do laptop como uma ferramenta para o ensino e aprendizagem, com um potencial de inovação curricular (MARINHO, 2006) a ser incorporado no Projeto Político Pedagógico [PPP] de cada escola.

Segundo Veiga (2007, p.15) “cabe postular que não é possível pensar e construir um projeto político-pedagógico sem partir de uma clara concepção de formação e de seus princípios fundantes". Portanto a ideia de se construir um Projeto de Gestão Integrada de Tecnologias [PROGITEC] que poderá incorporar os conhecimentos adquiridos ao longo do percurso de formação UCA ao PPP, de forma a assegurar a incorporação curricular das TDIC, foi preconizada no Projeto Formação Brasil (BRASIL,2007) com a perspectiva de ser adaptada em contextos regionais de formação.

$\mathrm{Na}$ experiência do projeto em Minas Gerais a formação de professores e gestores das escolas participantes ficou a cargo de uma equipe vinculada ao Programa de Pósgraduação em Educação da PUC Minas.

Por conta dos cronogramas de entrega de laptops nas escolas envolvidas no Projeto e da instalação da infraestrutura para acesso à internet, a formação de professores em Minas Gerais se deu por grupos de escolas.

Participaram do primeiro grupo de formação, os professores de duas escolas em Belo Horizonte, oito em Tiradentes, que era UCA Total, e uma em Uberaba, totalizando onze escolas UCA e cento e noventa e dois cursistas no início da formação.

O foco da pesquisa apresentado neste artigo é a experiência de formação no Módulo 5, denominado "Sistematização da Formação na Escola - Elaboração do PROGITEC", desenvolvida com o grupo 1 (um) de escolas. Ao final do Módulo, o último em oferta no percurso de formação, utilizou-se um questionário com o objetivo de conhecer a percepção, dos cursistas sobre a formação no módulo, sobre aspectos facilitadores e dificultadores no processo. A preocupação com esses aspectos decorria muito do fato da formação ser on-line, em um ambiente onde a expressiva maioria dos professores não tinha experiência.

\section{O MÓDULO DE CONSTRUÇÃO DO PROGITEC NA FORMAÇÃo UCA EM MINAS}

Na experiência UCA em Minas a proposta de formação passou por um redesenho em relação a proposta original do Projeto Formação Brasil. As mudanças relacionaram-se ao conteúdo e fluxo da oferta, observando-se princípios fundamentais do Projeto UCA Brasil, quanto a promoção de atividades que potencializem a inovação da prática pedagógica com o uso do laptop 1:1, utilizando a metodologia de projetos interdisciplinares nas escolas públicas participantes (MARINHO et al., 2012).

No redesenho da organização curricular da formação UCA Minas houve uma ampliação da carga horária total, que passou de cento e oitenta para duzentos e vinte horas, pois os Módulos 3A e 3B foram oferecidos a todos os cursistas, professores e gestores, com a justificativa de ampliar os conhecimentos para os professores que 
poderiam em algum momento profissional ocupar funções de gestão na escola e de preparar os gestores para o uso das TDIC quando retomassem atividades em sala de aula. Além disso, o fluxo de oferta de alguns módulos foi revisto.

Nos módulos anteriores ao 5, os cursistas, independente da escola e até mesmo do município eram alocados em turmas que exatamente buscavam a diversidade. Ou seja, ao invés de em cada turma nos Módulos estarem apenas os professores de uma determinada escola, eles eram "mesclados". A proposta era exatamente a de colocar cursistas de diferentes escolas e municípios, portanto de diferente realidades, em um mesmo espaço de formação, a turma, para induzir a troca, certamente rica, de experiências em diferentes contextos. Em outras palavras, se fazia uma "blend" de experiências.

Contudo, o Módulo 5 não permitia essa forma de organização das turmas. Como o produto do módulo deveria ser um projeto de gestão integrada de tecnologia articulado ao Projeto Político Pedagógico (PPP) da escola, os quarenta cursistas que chegaram ao Módulo 5, foram alocadas em turmas organizadas por município.

A partir deste agrupamento organizou-se, na "sala de aula" do Moodle, onze grupos de trabalho [GT], um em cada escola objetivando uma construção coletiva do PROGITEC de forma articulada ao PPP de cada escola. Neste sentido priorizaram-se atividades de reflexão e pesquisa entre pares para registro de práticas pedagógicas inovadoras que incorporaram a tecnologia móvel na realidade da escola ao longo do percurso de formação.

Tem-se como direcionamento pedagógico, no módulo 5, o delineamento de atividades que promovam a reflexão e o trabalho em equipe de acordo com projetos interdisciplinares que utilizam o laptop 1:1, discutidos no Módulo 4. As dificuldades, dúvidas percebidas pelos tutores e formadores que acompanharam cada turma eram discutidas entre todos da equipe, ou seja, coordenadores, formadores e tutores vinculados à PUC Minas. Realizava-se esta interação em reuniões presenciais ou no ambiente virtual através de e-mails. Durante o desenvolvimento das atividades no módulo 5, de forma semelhante aos demais módulos oferecidos on-line, foram criados dois fóruns, um fórum específico para as questões pedagógicas e outro para o compartilhamento de experiências ou dificuldades no uso do laptop educacional e do próprio ambiente virtual de aprendizagem, de forma a garantir uma comunicação efetiva entre os participantes e assegurar condições de melhor desenvolvimento das atividades de formação planejadas. Como se tratava do quinto módulo desenvolvido on-line, os problemas de ordem tecnológica praticamente não mais existiram. Os cursistas já estavam perfeitamente ambientados na sala de aula virtual.

\section{O PROGITEC NA SISTEMATIZAÇÃO DA FORMAÇÃO NA ESCOLA}

A elaboração do PROGITEC no módulo final da formação UCA em Minas Gerais manteve a mesma concepção para ele estabelecida no Projeto Formação Brasil, a exemplo de experiências em outros estados federativos (ALMEIDA, PRADO, ASSIS, 2012; COSTA, 2011; NASCIMENTO, 2011). Trata-se, portanto, de um projeto de gestão integrada das TDIC articulado ao PPP de cada escola, ou seja, contextualizado na realidade de cada uma delas.

Percebeu-se que, ao longo da formação no Projeto UCA, os cursistas vivenciavam experiências individuais e coletivas, presenciavam tensões a serem discutidas pela comunidade escolar. O PROGITEC tem um potencial para sistematizar 
estes conhecimentos que se integram ao PPP, com metas e ações que respaldam as inovações curriculares com a inserção das TDIC, contextualizadas no cenário local.

\begin{abstract}
O PROGITEC será uma proposta inédita, escrevendo uma página da história da escola por diversas mãos. As propostas e ações precisam estar em consonância com o PPP, o que dará sustentabilidade do uso dos laptops pelos alunos das escolas participantes do Projeto UCA. Este registro possibilitará que outros profissionais possam acessá-lo e reescrevê-lo de acordo com as necessidades e avanços na incorporação das tecnologias na escola [Notas de Conteúdo do Módulo5: Arquivo de Pesquisa, 2012].
\end{abstract}

Dada a importância desta construção, neste estudo em tela, tem-se o interesse em conhecer o que pensaram os concluintes sobre a formação que integralizaram após a construção do PROGITEC no Módulo 5 na formação UCA em Minas Gerais.

\title{
4. METODOLOGIA DA PESQUISA
}

A investigação foi um estudo de natureza qualitativa, na qual a ênfase na coleta dos dados, na sua compilação, análise e discussão está mais no processo do que nos resultados (BOGDAN; BIKLEN, 1994).

A pesquisa teve como objetivo conhecer a percepção de cursistas sobre a formação no módulo 5, mapeando elementos facilitadores e dificultadores nesta etapa da formação.

Para a coleta dos dados utilizou-se um questionário disponibilizado on-line na plataforma Moodle, após a postagem do PROGITEC na atividade final do módulo 5, no primeiro semestre de 2012. O questionário foi elaborado em dois blocos assim organizados:1- Avaliação dos cursistas sobre a formação no módulo 5 [questões fechadas]; 2- Registros dos aspectos facilitadores e dificultadores na formação do módulo 5 [questões abertas]. As respostas foram compiladas e categorizadas para a análise dos dados.

\section{SOBRE OS DADOS}

Considerando as respostas de trinta e nove concluintes do Módulo 5 do grupo 1 de escolas UCA, a saber as localizadas em Belo Horizonte, Tiradentes e Uberaba, organizaram-se os resultados obtidos no questionário com indicadores sobre a avaliação do desenho pedagógico na formação no módulo 5 e em relação aos aspectos facilitadores e dificultadores na formação deste mesmo módulo.

Quando perguntados se o grau de dificuldade das atividades condiziam com o nível de conhecimento dos cursistas (Gráfico 1), encontrou-se uma avaliação que precisa ser considerada pelos idealizadores da proposta, pois $67 \%$ responderam que o módulo atendeu plenamente esta questão; para 31\% atendeu parcialmente. Apenas cerca de $2 \%$ disseram que atendeu pouco. 


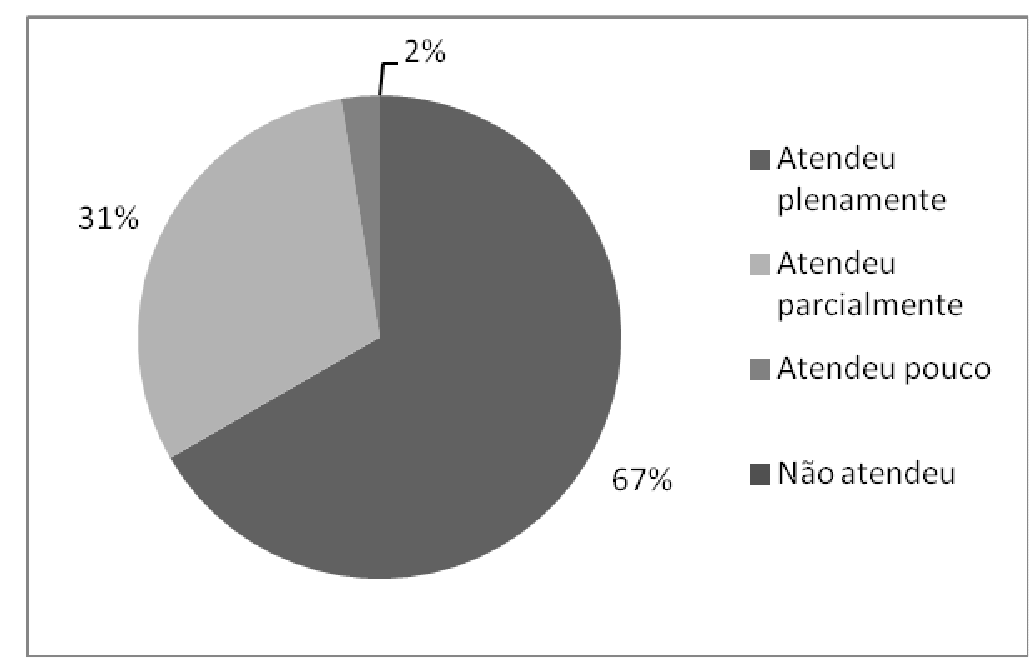

Gráfico 1: Grau de dificuldade das tarefas condizentes com o conhecimento do cursista

Constatou-se, pois, que as atividades propostas no Módulo 5 estavam adequadas ao público-alvo na formação. Ou seja, a realização das atividades foi pertinente ao grau de conhecimento esperado dos cursistas.

Em relação ao tempo para o desenvolvimento das atividades previstas no Módulo 5 (Gráfico 2), obteve-se o mesmo conjunto de respostas, ou seja, 67\% disseram que atendeu plenamente, $31 \%$ dos cursistas responderam que atendeu parcialmente e apenas $2 \%$ disseram que o tempo previsto atendeu pouco. Em síntese, o tempo previsto para a realização das atividades foi de maneira quase total considerado adequado. Este dado é relevante pois a questão do tempo é um aspecto a ser equacionado na formação à distância (MACHADO, 2005; PACHECO et al., 2008).

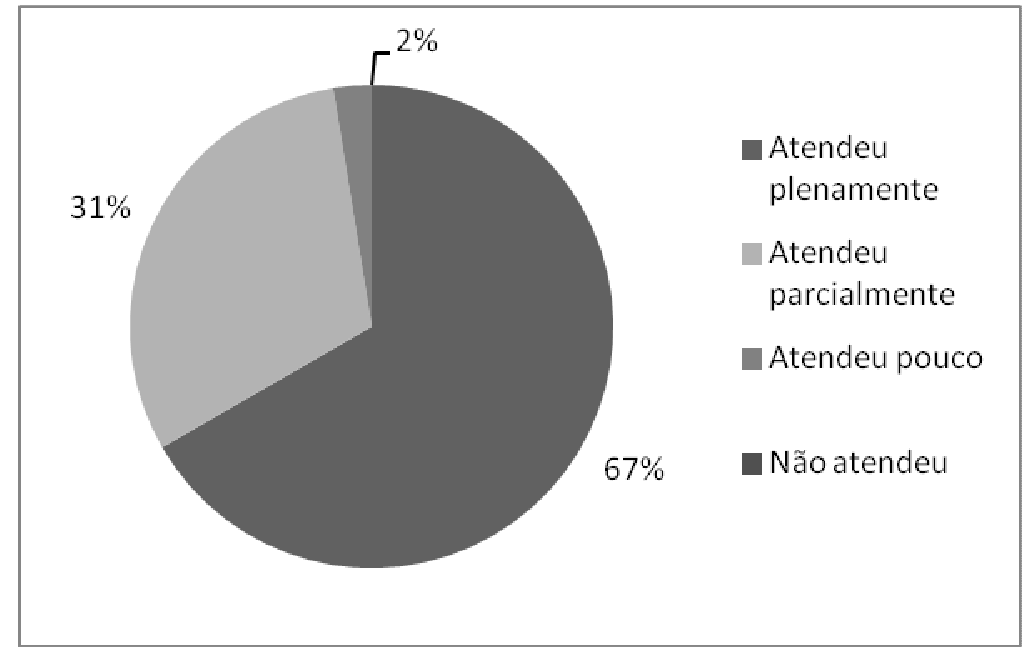

\section{Gráfico 2: Tempo para o desenvolvimento das atividades}

Ao analisar os aspectos positivos relacionados ao Módulo 5 pelos cursistas foi possível identificar cinco categorias no segundo bloco de questões.

A primeira categoria refere-se a relação de proximidade entre o PROGITEC e o PPP da escola. Em relação a primeira categoria, a elaboração coletiva do PROGITEC articulado ao Projeto Político Pedagógico da escola, os apontamentos registram o 
reconhecimento da importância da sistematização da formação, "extremamente importante o Projeto de Gestão Integrada inserido no PPP da escola, pois facilitará e obrigará a inserção de aprendizagens inovadoras em sala de aula"[Grifo nosso] (Prof.19).

Percebe-se que será necessário refletir coletivamente, com a mediação dos formadores, as concepções em relação a construção de projetos colaborativos na escola que adota as TDIC, para que não se torne uma "obrigação", ou seja, tarefa a mais a ser cumprida no trabalho escolar. Há que se considerar os percursos anteriores de projetos governamentais de formação continuada para que não se cometa os mesmos erros, a exemplo de colocar novas tecnologias na escola convivendo com velhos currículos (MARINHO, 2006).

A segunda categoria considera a aplicação prática e real do PROGITEC no ambiente escolar. Esta categoria se aproxima bastante da anterior, já que ambas demonstram a utilização do produto do Projeto UCA na realidade das escolas. Em relação à segunda categoria, verificou-se que os cursistas, em sua maioria, reconheceram a aplicabilidade da proposta dentro do contexto no qual estão inseridos. Alguns depoimentos deram especial destaque a isso: "Aplicação real na escola" (Prof.8) e "O módulo 5 possibilitou análise e reflexão sobre as ações do Projeto UCA nas escolas, bem como pensar em melhorias/mudanças a partir do PROGITEC" (Prof. 27). A aplicação prática foi um aspecto relevante para estes cursistas. Para eles ficou claro que o UCA favoreceu a construção de um conhecimento que pode ser aplicado no contexto de cada escola. Este dado é relevante, pois pode ser considerado um aspecto inovador na proposta de formação trazida com o projeto UCA, ao permitir que os conhecimentos obtidos através da formação fossem aplicados na realidade de cada escola. Em outras palavras, produziu-se algo concreto para a escola, não algo apenas para prestar conta aos formadores, como um mero trabalho a ser entregue.

Ainda em relação aos aspectos positivos, verificam-se mais duas categorias, a interatividade e a importância do trabalho em equipe. "Trabalho em equipe e reflexão para a elaboração do PROGITEC integrado ao PPP" (Prof. 33) e "União do grupo da escola para a realização do PROGITEC no Projeto Político Pedagógico" (Prof. 36). Outra categoria, é a importância de projetos na formação de professores: "Desenvolvimento de um projeto tecnológico" (Prof.15).

Já em relação aos aspectos que possam ter constituído dificuldade no percurso de formação, foram identificadas três categorias. A primeira relaciona-se à dificuldade em reunir os cursistas, ainda que da mesma escola, escola para elaborar o projeto. Assim justifica um cursista, professor 5: "Dificuldade de disponibilidade para reunir todos os componentes do grupo devido ao acúmulo de atividades dos profissionais". Neste caso, o que se pôde verificar é que dificuldades para os cursistas se reunirem e elaborarem o trabalho, apesar de serem da mesma escola, se deviam ao acúmulo de atividades no término do semestre letivo na escola, com o qual coincidiu a formação no Módulo 5, e ao fato de que vários deles têm atividades profissionais, em outro turno, em outra escola. Isso dificultou os encontros na escola para o desenvolvimento das atividades relacionadas ao PROGITEC. Tivessem os municípios, através das suas secretarias municipais de educação, efetivamente assegurado a disponibilidade de quatro horas semanais, da carga total do professor na escola, para as atividades de formação no Projeto UCA, conforme disposto no termo de adesão ao Projeto UCA, assinado pelo prefeito municipal, certamente esse obstáculo estaria transposto. Não é por outra razão que os cursistas apontam a "falta de tempo" como a segunda categoria no item dificultadores. "O tempo estipulado para a entrega da tarefa 3 - Progitec [pouco 
temp]" (Prof. 7). "O tempo para a elaboração do PROGITEC foi curto e nos levou a certos stress" (Prof. 8).

Essa falta de tempo foi um aspecto muito reforçado pelos cursistas. Porém é importante reconhecer que a questão de tempo é sempre um aspecto de difícil solução. A falta de tempo é, reconhecidamente, uma dos fatores dificultadores da permanência de estudantes em cursos à distância (PACHECO, et al., 2008). Por isso o tempo dado aos estudantes para as atividades torna-se um elemento importante no planejamento da formação.

Apesar da falta de tempo ter sido destacada como um aspecto negativo, em outra questão, verifica-se que este não foi um problema relevante durante a realização do módulo. Quando questionados sobre o tempo geral para realização do módulo, bem como para realização de cada tarefa, a maioria (67\%) dos cursistas afirmou que o tempo foi suficiente. Neste caso, pode-se inferir que os alunos que destacaram a falta de tempo são aqueles que afirmaram que o atendeu parcialmente ou atendeu pouco. Considera-se um desafio equacionar esta questão por não haver um consenso, de qualquer forma as respostas positivas no primeiro bloco de questões leva-nos a inferir que o tempo previsto para as atividades atendeu os propósitos do Módulo 5.

A terceira categoria de elemento dificultador elencada na análise qualitativa relaciona-se ao uso da tecnologia [TDIC] na escola. Esse ainda é um obstáculo destacado por uma parte significativa de cursistas.

É relevante, ainda, ressaltar que a utilização de uma tecnologia em uma aula, começa a ser concebida muito antes de ela chegar até a sala de aula. É um processo de planejamento do professor que começa com a escolha da tecnologia, passando pela verificação de sua aplicabilidade para a aula em questão, envolvendo a experimentação se suas características técnicas e tecnológicas para o conteúdo a ser trabalhado. É um processo trabalhoso, de pesquisa, análise e reflexão, que envolve um grande investimento de tempo e energia do professor.

Outras dificuldades encontradas em pesquisas relacionadas ao Projeto UCA, como a precariedade de estruturas das escolas, a ausência de suporte técnico e ainda a resistência dos professores (NEVES, et al., 2012), não foram registradas pelos cursistas do grupo [um] de escolas em Minas Gerais.

\section{CONSIDERAÇÕES FINAIS}

O Projeto UCA, na sua fase do experimento-piloto, está sendo encerrado em $2013 \mathrm{em}$ Minas Gerais. Os estudos que apresentam relatos de experiências tornam-se documentos históricos que poderão auxiliar no planejamento de novas propostas de formação continuada com adoção de tecnologias móveis, notadamente no uso 1:1.

Considerando os dados obtidos através deste estudo, é possível destacar a importância do PROGITEC para os cursistas e para as escolas que utilizam as tecnologias móveis na sala de aula com perspectivas de inovação curricular.

Foi possível perceber que o desenvolvimento deste projeto articulado com o PPP oferece uma chance, concreta e importante, de sistematização de conhecimento para os cursistas, tornou-se um aspecto significativo enquanto formação pessoal e profissional. Foi possível, também, evidenciar que a atividade de elaboração de projetos que integram as TDIC ao trabalho pedagógico é realidade em algumas escolas UCA em Minas Gerais. 
A utilização efetiva das tecnologias no ambiente escolar pode estar relacionada com a necessidade de elaboração coletiva de um projeto nos moldes do PROGITEC. Na sua proposta de formação, o Projeto UCA desafiou os cursistas a refletirem sobre as práticas inovadoras com o uso das TDIC e registrá-las em um trabalho de construção de fato compartilhado. Desta forma, acredita-se que existe uma chance de que o PROGITEC se transforme em ações concretas na escola. Essa experiência de integração e sistematização de conhecimentos certamente deverá ser considerada em outros contextos de formação de educadores, especialmente para o uso educacional das TDIC.

Os aspectos dificultadores registrados pelos cursistas ao longo do percurso do Módulo 5 tornam-se desafios a serem superados no redesenho curricular e no desenvolvimento de novos cursos de formação continuada de professores que utilizam as modalidades presencial e/ou a distância, objetivando a inovação do ensino e aprendizagem com TDIC nas escolas. No próprio Projeto UCA em Minas, os achados dessa pesquisa permitiram ajustes quando das novas ofertas do Módulo 5. Aprendemos com os cursistas e nos preparamos para melhor formar os demais, nas subsequentes ofertas do Módulo 5, para os demais grupos de escolas integradas ao Projeto UCA em Minas Gerais.

\section{REFERÊNCIAS}

ABDALlA,M. F.B.(2007). A Construção do Projeto Político Pedagógico e a Formação Permanente dos Professores: Possibilidades e Desafios.In VEIGA,I.P.A.(Org.). Quem Sabe Faz a Hora de Construir o Projeto Político-Pedagógico.Campinas:Papirus.p.153173.

ALMEIDA, M. E.B. (2010). Integração de currículo e tecnologias: a emergência de web currículo. Anais do XV Endipe - Encontro Nacional de Didática e Prática de Ensino. Belo Horizonte: UFMG.

ALMEIDA, M. E.B.; PRADO, M. E. B.B.; ASSIS, M. P. (2012).O laptop na Escola e o Projeto de Gestão Integrada de Tecnologia.Anais do workshops do CBIE.

BOGDAN, R.C.; BIKLEN, S. K. (1994).Investigação Qualitativa em Educação: uma introdução à teoria e aos métodos. Portugal: Porto Editora.

BRASIL. MEC. (2007). Princípios orientadores para o uso pedagógico do laptop na educação escolar. Brasília: MEC/SEED.

COSTA, T. Et al. (2011). Formação tecnológica de Professores do Município do Rio Tinto: um relato de experiência.Anais do XXII SBIE - XVII WIE , Aracaju.

MACHADO, L. D. (2005). Concepções de Espaço e Tempo nas Teorias de Educação a Distância. Anais do XII ABED, Florianópolis. Disponível em < http://www.abed.org.br/congresso2005/por/pdf/147tca3.pdf $>$. Acesso em 02 de out. de 2013.

MARINHO, S. P. P. Novas tecnologias e velhos currículos; já é hora de sincronizar(2006).Revista E-curriculum, ISSN 1809-3876, São Paulo, V. 2, n.3, dezembro. Disponível em <http://www.pucsp.br/ecurriculum>. Acesso em 27 de set. de 2010 . 
MARINHO, S. P. P. et al. (2011). Uma Proposta Contextualizada de Formação on-line de Professores e Gestores no Projeto UCA em Minas Gerais: possibilidades e desafios.Anais do XXII SBIE - XVII WIE, Aracaju.

MARINHO, S. P. P.; MARINHO, A. M. S. TÁRCIA, L.; SILVA, C. L; VELLOSO, M. J. (2012) A formação on-line no Projeto UCA em Minas Gerais: contextualização, para além do ambiente virtual. In: BOTTENTUIT JUNIOR, J. B.; COUTINHO, C. P. (Org.). Educação online: conceitos, metodologias, ferramentas e aplicações. Curitiba: CRV, p. 173-186.

NASCIMENTO, K. A. S. et al (2011). Um olhar sobre a formação docente do programa UCA em uma escola municipal de Fortaleza.Anais do XXII SBIE - XVII WIE, Aracaju.

NEVES, Y. P. C. et al. Um olhar sobre a formação do PROUCA: dificuldades e estratégias. Anais do Workshop do Congresso Brasileiro de Informática na Educação, Rio de Janeiro, 2012.

PACHECO, A, S. V. et al. Fatores dificultadores à permanência dos alunos no curso de graduação em administração a distância da Universidade Federal de Santa Catarina. Novas tecnologias na educação, v. 6, n. 1, 2008.

SAMPAIO, F.; ELIA, M. F. (Orgs.). (2012).Projeto Um Computador por Aluno: Pesquisas e Perspectivas. Rio de Janeiro: NCE/UFRJ. Disponível em<www.nce.ufrj.br/ginape/livro/prouca $>$ Acesso em 21 de set. de 2013.

VEIGA,I. P.A.(Org.).(2007). Quem Sabe Faz a Hora de Construir o Projeto PolíticoPedagógico. Campinas:Papirus. p.11-37 